\title{
Factors affecting high-sensitivity cardiac troponin $T$ elevation in Japanese metabolic syndrome patients
}

This article was published in the following Dove Press journal:

Diabetes, Metabolic Syndrome and Obesity: Targets and Therapy

10 March 2015

Number of times this article has been viewed

\author{
Takashi Hitsumoto' \\ Kohji Shirai ${ }^{2}$ \\ 'Hitsumoto Medical Clinic, \\ Yamaguchi, Japan; ${ }^{2}$ Department of \\ Vascular Function (donated), Sakura \\ Hospital, Toho University School of \\ Medicine, Chiba, Japan
}

Purpose: The blood concentration of cardiac troponin T (ie, high-sensitivity cardiac troponin T [hs-cTnT]), measured using a highly sensitive assay, represents a useful biomarker for evaluating the pathogenesis of heart failure or predicting cardiovascular events. However, little is known about the clinical significance of hs-cTnT in metabolic syndrome. The aim of this study was to examine the factors affecting hs-cTnT elevation in Japanese metabolic syndrome patients.

Patients and methods: We enrolled 258 metabolic syndrome patients who were middle-aged males without a history of cardiovascular events. We examined relationships between hs-cTnT and various clinical parameters, including diagnostic parameters of metabolic syndrome.

Results: There were no significant correlations between hs-cTnT and diagnostic parameters of metabolic syndrome. However, hs-cTnT was significantly correlated with age $(P<0.01)$, blood concentrations of brain natriuretic peptide $(P<0.01)$, reactive oxygen metabolites (markers of oxidative stress, $P<0.001$ ), and the cardio-ankle vascular index (marker of arterial function, $P<0.01)$. Furthermore, multiple regression analysis revealed that these factors were independent variables for hs-cTnT as a subordinate factor.

Conclusion: The findings of this study indicate that in vivo oxidative stress and abnormality of arterial function are closely associated with an increase in hs-cTnT concentrations in Japanese metabolic syndrome patients.

Keywords: troponin, metabolic syndrome, risk factor, oxidative stress, cardio-ankle vascular index

\section{Introduction}

The pathogenesis of metabolic syndrome is considered as a multiple risk factor clustering, which is caused by visceral fat accumulation, in Japan. ${ }^{1}$ The Japanese Committee for the Diagnostic Criteria of Metabolic Syndrome adopted a visceral fat area of $100 \mathrm{~cm}^{2}$ as the cutoff point, which was estimated by computed tomography in both men and women. Furthermore, the waist circumference corresponding to a visceral fat area of $100 \mathrm{~cm}^{2}$ was confirmed as $85 \mathrm{~cm}$ in men and $90 \mathrm{~cm}$ in women. According to this concept, in 2005, the Japanese Committee for the Diagnostic Criteria of Metabolic Syndrome defined metabolic syndrome as the presence of two or more clinical abnormalities (three abnormalities: dyslipidemia [serum triglyceride concentrations $\geq 150 \mathrm{mg} / \mathrm{dL}$ and/or serum high-density lipoprotein cholesterol concentrations $<40 \mathrm{mg} / \mathrm{dL}$ or under treatment], elevated blood pressure levels [systolic blood pressure $\geq 130 \mathrm{mmHg}$ and/or diastolic pressure $\geq 85 \mathrm{mmHg}$ or under treatment], and elevated blood glucose levels [fasting blood glucose $\geq 110 \mathrm{mg} / \mathrm{dL}$ or under treatment]), in addition to visceral fat obesity (waist circumference: $85 \mathrm{~cm}$ or more in men and $90 \mathrm{~cm}$ or more in women). ${ }^{2}$ Metabolic syndrome is considered as not only an important cardiovascular risk factor
Correspondence: Takashi Hitsumoto Hitsumoto Medical Clinic, 2-7-7, Takezakicyou, Shimonoseki-City, Yamaguchi 750-0025, Japan

Tel +8I 832230657

Fax +81832330657

Email thitsu@jcom.home.ne.jp 
but also a contributor to the development of type 2 diabetes in Japan, ${ }^{3-5}$ even though the definition of metabolic syndrome in Japan is different from that in other countries.

Clinically, the blood concentration of cardiac troponin $\mathrm{T}$, a component of the troponin complex, is used as a diagnostic tool for acute myocardial infarction, because cardiac troponin $\mathrm{T}$ is rapidly released from the myocardium to the blood following myocardial damage. ${ }^{6}$ Furthermore, recent clinical and epidemiological studies have demonstrated that the blood concentration of cardiac troponin T (ie, highsensitivity cardiac troponin $\mathrm{T}$ [hs-cTnT]), measured using a highly sensitive assay, represents a useful biomarker for evaluating the pathogenesis of heart failure or predicting cardiovascular events. ${ }^{7-9}$ Several reports exist concerning relationships between hs-cTnT and clinical parameters such as age-related markers, in Japan or other countries..$^{8,10,11}$ However, little is known about the clinical significance of hs-cTnT in metabolic syndrome. In the present study, we attempted to clarify the factors important for hs-cTnT elevation in metabolic syndrome from the perspective of primary cardiovascular events.

\section{Patients and methods}

\section{Study population}

This study was conducted at the Hitsumoto Medical Clinic in Shimonoseki City, Japan, between September 2011 and August 2013. The study population comprised 258 metabolic syndrome patients who were middle-aged males diagnosed using the Japanese metabolic syndrome criteria. ${ }^{2}$ Subjects with a history of cardiovascular disease or those using medications such as antihyperlipidemic, antihypertensive, or antidiabetic drugs were excluded. All participants provided informed consent, and the study protocol was approved by the Local Ethics Committee of the Hitsumoto Medical Clinic.

\section{Estimation of cardiovascular risk factors}

Diagnostic parameters of metabolic syndrome in the Japanese criteria and various clinical parameters, including hs-cTnT concentrations, were examined. In this study, the cardio-ankle vascular index (CAVI) was evaluated as a marker of arterial function. CAVI was measured by a standard method described previously. ${ }^{12}$ Briefly, the brachial and ankle pulse waves were determined using inflatable cuffs with the pressure maintained between 30 and $50 \mathrm{mmHg}$ to ensure that the cuff pressure had a minimal effect on the systemic hemodynamics. Blood pressure and pulse pressure were determined simultaneously. ${ }^{12}$ These measurements were obtained with the subject in the supine position. CAVI was measured after the subject had rested for 10 minutes in a quiet room.

\section{Blood sampling}

Blood samples were collected from the antecubital vein in the morning after 12 hours of fasting. Total cholesterol and triglyceride concentrations were measured using standard enzymatic methods. Serum high-density lipoprotein cholesterol concentrations were measured by selective inhibition. Serum low-density lipoprotein cholesterol concentrations were calculated using the Friedewald formula; ${ }^{13}$ subjects with serum triglyceride concentrations $\geq 400 \mathrm{mg} / \mathrm{dL}$ were excluded because of the low sensitivity of this method. Glucose and insulin concentrations were measured using the glucose oxidase method and an enzyme immunoassay, respectively. To measure insulin resistance, we calculated homeostatic model assessment of insulin resistance (HOMA-IR) as follows: ${ }^{14} \mathrm{HOMA}-\mathrm{IR}=$ fasting glucose concentration $(\mathrm{mg} / \mathrm{dL}) \times$ fasting insulin concentration $(\mu \mathrm{g} / \mathrm{mL}) / 405$. Estimated glomerular filtration rate (eGFR) was calculated using the adjusted Modification of Diet in Renal Disease Study equation, which was proposed by the working group of the Japanese Chronic Kidney Disease Initiative. ${ }^{15}$ The blood concentration of brain natriuretic peptide was measured using a commercial kit (SHIONOSPOT Reader; Shionogi and Co, Ltd, Osaka, Japan). High-sensitivity C-reactive protein (hs-CRP) concentration was measured using high-sensitivity, latex-enhanced immunonephelometry. The derivated reactive oxygen metabolites test, which reflects blood hydroperoxide concentrations, was performed using a commercial device (Diacron, Grosseto, Italy) $.{ }^{16} \mathrm{hs}-\mathrm{cTnT}$ concentration was measured using a commercial kit (Roche Diagnostics, Rotkreuz, Switzerland). ${ }^{17}$ In this assay, the lower limit of detection was $0.003 \mathrm{ng} / \mathrm{mL}$.

\section{Statistical analysis}

A commercially available statistical software program (Stat View-J 5.0; HULINKS Inc., Tokyo, Japan) was used for all statistical analyses. Data are expressed as mean \pm standard deviation. Between-group comparisons were performed using the Student's $t$-test or Mann-Whitney's $U$-test, and the correlation coefficient was estimated using Spearman's rank correlation analysis. To clarify the independent factors for hs-cTnT elevation, we performed multiple regression analysis for hs-cTnT as a subordinate factor. A $P$-value of $<0.05$ was considered statistically significant.

\section{Results}

Patient characteristics are shown in Table 1. hs-cTnT was detected in 226 patients ( $88 \%$ ). Age, hs-CRP concentrations, 
Table I Patient characteristics

\begin{tabular}{|c|c|c|c|}
\hline & All & $\begin{array}{l}\text { hs-cTnT } \\
\text { nondetection }\end{array}$ & $\begin{array}{l}\text { hs-cTnT } \\
\text { detection }\end{array}$ \\
\hline $\mathrm{N}$ & 258 & 32 & 226 \\
\hline Age (years) & $63 \pm 11$ & $56 \pm 7$ & $64 \pm 11 *$ \\
\hline Smoking (\%) & $77(30)$ & $7(22)$ & $70(31)$ \\
\hline Body mass index $\left(\mathrm{Kg} / \mathrm{m}^{2}\right)$ & $24.7 \pm 3.0$ & $24.0 \pm 3.0$ & $24.8 \pm 3.0$ \\
\hline \multicolumn{4}{|l|}{ Diagnostic parameters of Mets } \\
\hline Waist circumference (cm) & $89 \pm 5$ & $89 \pm 4$ & $89 \pm 5$ \\
\hline Triglyceride (mg/dL) & $203 \pm 60$ & $193 \pm 55$ & $204 \pm 61$ \\
\hline HDL cholesterol (mg/dL) & $44 \pm 14$ & $43 \pm 10$ & $44 \pm 15$ \\
\hline Systolic BP $(\mathrm{mmHg})$ & $|4| \pm 20$ & $|4| \pm 18$ & $|4| \pm 2 \mid$ \\
\hline Diastolic BP (mmHg) & $89 \pm 14$ & $87 \pm 13$ & $89 \pm 14$ \\
\hline Fasting blood glucose (mg/dL) & $111 \pm 15$ & $110 \pm 16$ & $111 \pm 15$ \\
\hline Immunoreactive insulin $(\mu \mathrm{g} / \mathrm{mL})$ & $9.6 \pm 4.2$ & $9.8 \pm 3.4$ & $9.6 \pm 4.3$ \\
\hline Log-HOMA-IR & $0.4 \pm 0.3$ & $0.4 \pm 0.2$ & $0.4 \pm 0.3$ \\
\hline Total cholesterol (mg/dL) & $226 \pm 43$ & $230 \pm 44$ & $225 \pm 42$ \\
\hline LDL cholesterol (mg/dL) & $|4| \pm 40$ & $149 \pm 40$ & $140 \pm 40$ \\
\hline Log-hs-CRP (mg/L) & $-I . I \pm 0.4$ & $-1.3 \pm 0.6$ & $-1.0 \pm 0.4^{* *}$ \\
\hline d-ROMs test (U Carr) & $321 \pm 77$ & $266 \pm 46$ & $329 \pm 77^{*}$ \\
\hline Log-BNP (pg/mL) & $1.5 \pm 0.5$ & $1.2 \pm 0.3$ & $1.5 \pm 0.5 * * *$ \\
\hline eGFR $\left(\mathrm{mL} / \mathrm{min} / \mathrm{l} .73 \mathrm{~m}^{2}\right)$ & $60 \pm 21$ & $75 \pm 17$ & $58 \pm 21 *$ \\
\hline Cardio-ankle vascular index & $9.1 \pm 1.5$ & $8.1 \pm 1.1$ & $9.2 \pm 2.1 *$ \\
\hline Log-hs-cTnT (ng/mL) & $-2.1 \pm 0.2$ & - & $-2.1 \pm 0.2$ \\
\hline
\end{tabular}

Note: Data are expressed mean \pm SD. $* P<0.001 ; * * P<0.05 ; * * * P<0.01$.

Abbreviations: Mets, metabolic syndrome; hs-cTnT, high-sensitivity cardiac troponin T; BP, blood pressure; HOMA-IR, homeostatic model assessment of insulin resistance; LDL, low-density lipoprotein; HDL, high-density lipoprotein; hs-CRP, high sensitivity C-reactive protein; d-ROMs, derivatives of reactive oxygen metabolites; BNP, brain natriuretic peptide; eGFR, estimated glomerular filtration rate.

ROM serum concentrations, blood concentrations of brain natriuretic peptide, and CAVI were significantly higher, and eGFR was significantly lower in patients with detectable hs-cTnT. However, diagnostic parameters of metabolic syndrome were not significantly different between the two groups. Correlations between hs-cTnT and various clinical parameters in hs-cTnT-positive patients are shown in Table 2. Age, hs-CRP concentrations, ROM serum concentrations, blood concentrations of brain natriuretic peptide, eGFR, and CAVI were significantly correlated with hs-cTnT, although diagnostic parameters of metabolic syndrome had no significant correlations with hs-cTnT.

The results of multiple regression analysis are shown in Table 3. Blood concentrations of brain natriuretic peptide, ROM serum concentrations, CAVI, and age were selected as independent variables for hs-cTnT as a subordinate factor.

\section{Discussion}

Recently, Pervanidou et $a{ }^{18}$ examined the relationship of circulating concentrations of hs-cTnT with metabolic syndrome in childhood. They reported that hs-cTnT in obese children with metabolic syndrome was higher than that in
Table 2 Correlation between hs-cTnT and various clinical parameters in hs-cTnT detectable patients

\begin{tabular}{lll}
\hline & $\boldsymbol{r}$ & $\boldsymbol{P}$ value \\
\hline Age & 0.35 & $<0.01$ \\
Smoking $(\mathrm{No}=0$, Yes =I) & 0.06 & 0.39 \\
Body mass index & $0.1 \mathrm{I}$ & 0.10 \\
Waist circumference & 0.09 & 0.20 \\
Triglyceride & $-0.2 \mathrm{I}$ & 0.06 \\
HDL cholesterol & $0.1 \mathrm{I}$ & 0.32 \\
Systolic BP & -0.07 & 0.57 \\
Diastolic BP & 0.02 & 0.86 \\
Fasting blood glucose & -0.02 & 0.89 \\
Immunoreactive insulin & -0.10 & 0.37 \\
Log-HOMA-IR & $-0.1 \mathrm{I}$ & 0.30 \\
Total cholesterol & $-0.1 \mathrm{I}$ & 0.34 \\
LDL cholesterol & -0.07 & 0.56 \\
Log-hs-CRP & 0.18 & $<0.0 \mathrm{I}$ \\
d-ROMs test & 0.43 & $<0.00 \mathrm{I}$ \\
Log-BNP & 0.32 & $<0.0 \mathrm{I}$ \\
eGFR & -0.24 & $<0.05$ \\
Cardio-ankle vascular index & 0.36 & $<0.0 \mathrm{I}$ \\
\hline
\end{tabular}

Note: $(n=226)$.

Abbreviations: hs-cTnT, high-sensitivity cardiac troponin T; BP, blood pressure; HOMA-IR, homeostatic model assessment of insulin resistance; LDL, low-density lipoprotein; HDL, high-density lipoprotein; hs-CRP, high sensitivity C-reactive protein; d-ROMs, derivatives of reactive oxygen metabolites; BNP, brain natriuretic peptide; eGFR, estimated glomerular filtration rate.

obese children without metabolic syndrome and nonobese children; moreover, hs-cTnT did not differ between obese children without metabolic syndrome and nonobese children. These results suggest that the presence of metabolic syndrome resulted in hs-cTnT elevation at an early stage. Among diagnostic parameters of metabolic syndrome, high blood glucose concentrations and high blood pressure were reported to cause myocardial damage via dysfunction of microcirculation, oxidative stress, or other pathways. ${ }^{19-21}$ In clinical studies, however, relationships among blood glucose concentrations, blood pressure levels, and blood concentrations of cardiac

Table 3 Multiple regression analysis for hs-cTnT

\begin{tabular}{llll}
\hline & $\begin{array}{l}\text { Standard correlation } \\
\text { coefficient }\end{array}$ & $\boldsymbol{t}$ value & $\boldsymbol{P}$ value \\
\hline $\begin{array}{l}\text { Explanatory factor } \\
\text { d-ROMs test }\end{array}$ & 0.37 & 5.7 & $<0.001$ \\
Log-BNP & 0.16 & 2.6 & $<0.01$ \\
CAVI & 0.13 & 2.2 & $<0.05$ \\
Age & 0.11 & 2.0 & $<0.05$ \\
eGFR & -0.10 & -1.4 & 0.16 \\
Log-hs-CRP & 0.06 & 0.8 & 0.40 \\
\hline
\end{tabular}

Note: $R^{2}=0.28, F$ value $=16.2, P<0.001$.

Abbreviations: hs-cTnT, high-sensitivity cardiac troponin T; hs-CRP, high sensitivity C-reactive protein; d-ROMs, derivatives of reactive oxygen metabolites; BNP, brain natriuretic peptide; eGFR, estimated glomerular filtration rate; CAVI, cardio-ankle vascular index. 
troponin were controversial. ${ }^{22-25}$ Wallace et al ${ }^{22}$ reported that diabetes mellitus was independently associated with cTnT elevation in the general population. However, Everett et $\mathrm{al}^{23}$ reported that no significant relationship was observed between hemoglobin $\mathrm{A}_{1 \mathrm{c}}$ levels and hs-cTnT in nondiabetic subjects. McKie et $\mathrm{al}^{24}$ reported that hypertension was significantly associated with hs-cTnT in the general population. However, Hoshide et $\mathrm{al}^{25}$ reported that blood pressure-lowering therapy using losartan plus hydrochlorothiazide did not lead to a significant decrease in hs-cTnT, even though blood pressure levels were decreased. Insulin resistance has been considered to have an important role in the pathogenesis of metabolic syndrome. Furthermore, some clinical studies reported a correlation between insulin resistance and myocardial damage. ${ }^{26,27}$ In the present study, however, HOMA-IR showed no significant correlation with hs-cTnT. It is well known that abnormal adipocytokine secretion is associated with the pathogenesis of metabolic syndrome. Furthermore, some basic or clinical studies reported relationships between adipocytokines such as adiponectin or resistin and myocardial damage..$^{28,29}$ Abnormal adipocytokine secretion may be an important factor for hs-cTnT elevation in metabolic syndrome. In this study, adipocytokine concentrations were not assessed; therefore, further studies are warranted to evaluate the relationship of adipocytokines with hs-cTnT.

Oxidative stress is known to be an important component in the progression of heart failure, and several pathways by which oxidative stress leads to myocardial damage have been identified, including dysfunction of the mitochondrial electron transport complex, activity of nicotinamide adenine dinucleotide phosphate oxidase, and apoptosis of myocardial cells. ${ }^{30-32}$ Furthermore, this study revealed the importance of oxidative stress for myocardial damage in metabolic syndrome and subclinical heart failure. Among a number of markers of oxidative stress, the derivated reactive oxygen metabolites test is considered clinically useful to evaluate oxidative stress in vivo, because the measurement of ROM serum concentrations is accurate and simple and it can be performed rapidly. ${ }^{16,33}$ Furthermore, recent clinical studies have reported a relationship between ROM and cardiovascular disease. ${ }^{34,35}$ Therefore, the measurement of ROM serum concentrations is expected to predict the degree of subclinical myocardial damage or primary cardiovascular events in metabolic syndrome.

The stiffness index $\beta$ is known to reflect the stiffness of the aortic artery, and CAVI is reported to reflect the stiffness index $\beta$ of the thoracic aorta or the common carotid artery. ${ }^{36} \mathrm{CAVI}$ is considered as a useful physiological marker for evaluating arterial stiffness, except in patients with chronic arterial fibrilla- tion or peripheral arterial disease, because of the low reliability of CAVI. In recent years, several studies have indicated the importance of left ventricular dysfunction in the occurrence of heart failure or the progression of myocardial damage, ${ }^{37}$ furthermore, increases in aortic artery stiffness are known to cause left ventricular dysfunction. Sakane et al ${ }^{38}$ reported a significant relationship between CAVI and left ventricular dysfunction using ultrasonic echocardiography. Therefore, the relationship between hs-cTnT and CAVI identified in this study was considered to reflect myocardial damage via left ventricular dysfunction by an increase in vascular resistance or afterload. Another clinical study reported that CAVI reflected endothelial dysfunction. ${ }^{39}$ Endothelial dysfunction has also been known to cause left ventricular dysfunction or myocardial damage; ${ }^{40,41}$ therefore, the significant correlation of hs-cTnT with CAVI in metabolic syndrome patients may be partly explained by endothelial dysfunction.

This study had several limitations. First, ultrasonic echocardiography, coronary angiography, or multidetector computed tomography angiography was not performed; therefore, cardiovascular diseases such as heart failure or coronary artery disease may have remained undetected in patients. Second, female subjects were not included. The proportion of metabolic syndrome patients in the general Japanese female population is very small (incidence: $12.1 \%$ in males, $1.7 \%$ in females). ${ }^{42}$ Therefore, analysis of metabolic syndrome in females diagnosed by the Japanese criteria is very difficult in the single-unit range. The relationship between hs-cTnT and metabolic syndrome in the Japanese female population will be discussed in large-scale studies. Third, this study was cross-sectional, and its sample size was relatively small. A large number of prospective studies, including interventional therapies, are required to clarify the clinical significance of hs-cTnT, CAVI, and ROMs with metabolic syndrome.

\section{Conclusion}

The study findings indicate that in vivo oxidative stress and abnormalities of arterial function are closely associated with increases in hs-cTnT concentration in Japanese metabolic syndrome patients.

\section{Disclosure}

The authors have no conflicts of interest to declare.

\section{References}

1. Nakamura T, Tokunaga K, Shimomura I, et al. Contribution of visceral fat accumulation to the development of coronary artery disease in nonobese men. Atherosclerosis. 1994;107(2):239-246. 
2. Matsuzawa Y. Metabolic syndrome-definition and diagnostic criteria in Japan. J Atheroscler Thromb. 2005;12(6):301.

3. Mottillo S, Filion KB, Genest J, et al. The metabolic syndrome and cardiovascular risk a systematic review and meta-analysis. $J$ Am Coll Cardiol. 2010;56(14):1113-1132.

4. Takeuchi H, Saitoh S, Takagi S, et al. Metabolic syndrome and cardiac disease in Japanese men: applicability of the concept of metabolic syndrome defined by the National Cholesterol Education Program-Adult Treatment Panel III to Japanese men - the Tanno and Sobetsu Study. Hypertens Res. 2005;28(3):203-208.

5. Hitsumoto T, Takahashi M, Iizuka T, Shirai K. Relationship between metabolic syndrome and early stage coronary atherosclerosis. $J$ Atheroscler Thromb. 2007;14(6):294-302.

6. Reichlin T, Hochholzer W, Bassetti S, et al. Early diagnosis of myocardial infarction with sensitive cardiac troponin assays. $N$ Eng J Med. 2009;361(9):858-867.

7. Latini R, Masson S, Anand IS, et al. Val-HeFT Investigators. Prognostic value of very low plasma concentrations of troponin $\mathrm{T}$ in patients with stable chronic heart failure. Circulation. 2007;116(11):1242-1249.

8. Sato Y, Yamamoto E, Sawa T, et al. High-sensitivity cardiac troponin $\mathrm{T}$ in essential hypertension. J Cardiol. 2011;58(3):226-231.

9. Saunders JT, Nambi V, de Lemos JA, et al. Cardiac troponin T measured by a highly sensitive assay predicts coronary heart disease, heart failure, and mortality in the Atherosclerosis Risk in Communities Study. Circulation. 2011;123(13):1367-1376.

10. Setsuta K, Kitahara Y, Arae M, Ohbayashi T, Seino Y, Mizuno K. Elevated cardiac troponin T predicts adverse outcomes in hypertensive patients. Int Heart J. 2011;52(3):164-169.

11. Chenevier-Gobeaux C, Bailleul S, Mzabi A, Blanc MC, Lefevre G. Upper reference limits of high-sensitivity cardiac troponin $\mathrm{T}$ in a general population: comparison with those of sensitive cardiac troponin I. Clin Lab. 2013;59(3-4):333-336.

12. Shirai K, Utino J, Otsuka K, Takata M. A novel blood pressureindependent arterial wall stiffness parameter; cardio-ankle vascular index (CAVI). J Atheroscler Thromb. 2006;13(2):101-107.

13. Fridewald WT, Levy RI, Fredrickson DS. Estimation of the concentration of low density lipoprotein cholesterol in plasma, without use of the preparative ultracentrifuge. Clin Chem. 1972;18(6):499-502.

14. Matthews DR, Hosker JP, Rudenski AS, Naylor BA, Treacher DF, Turner RC. Homeostasis model assessment: insulin resistance and betacell function from fasting plasma glucose and insulin concentrations in man. Diabetologia. 1985;28(7):412-419.

15. Imai E, Horio M, Nitta K, et al. Estimation of glomerular filtration rate by the MDRD study equation modified for Japanese patients with chronic kidney disease. Clin Exp Nephrol. 2007;11(1):41-50.

16. Cesarone MR, Belcaro G, Carratelli M, et al. A simple test to monitor oxidative stress. Int Angiol. 1999;18(2);127-130.

17. Mingels A, Jacobs L, Michielsen E, Swaanenburg J, Wodzig W, van Dieijen-Visser M. Reference population and marathon runner sera assessed by highly sensitive cardiac troponin $\mathrm{T}$ and commercial cardiac troponin T and I assays. Clin Chem. 2009;55(1):101-108.

18. Pervanidou P, Akalestos A, Bastaki D, et al. Increased circulating high-sensitivity troponin $\mathrm{T}$ concentrations in children and adolescents with obesity and the metabolic syndrome: a marker for early cardiac damage? Metabolism. 2013;62(4):527-531.

19. Cai L, Wang Y, Zhou G, et al. Attenuation by metallothionein of early cardiac cell death via suppression of mitochondrial oxidative stress results in a prevention of diabetic cardiomyopathy. $\mathrm{J} \mathrm{Am} \mathrm{Coll} \mathrm{Cardiol}$. 2006;48(8):1688-1697.

20. Heyliger CE, Pierce GN, Singal PK, Beamish RE, Dhalla NS. Cardiac alpha- and beta-adrenergic receptor alterations in diabetic cardiomyopathy. Basic Res Cardiol. 1982;77(6):610-618.

21. Higuchi M, Yasuda O, Kawamoto H, et al. Tissue inhibitor of metalloproteinase-3 deficiency inhibits blood pressure elevation and myocardial microvascular remodeling induced by chronic administration of nomega-nitro-L-arginine methyl ester in mice. Hypertens Res. 2007;30(6):563-571.
22. Wallace TW, Abdullah SM, Drazner MH, et al. Prevalence and determinants of troponin T elevation in the general population. Circulation. 2006;113(16):1958-1965.

23. Everett BM, Cook NR, Magnone MC, et al. Sensitive cardiac troponin T assay and the risk of incident cardiovascular disease in women with and without diabetes mellitus: the Women's Health Study. Circulation. 2011;123(24):2811-2818.

24. McKie PM, Heublein DM, Scott CG, et al. Defining high-sensitivity cardiac troponin concentrations in the community. Clin Chem. 2013;59(7): 1099-1107.

25. Hoshide S, Fukutomi M, Eguchi K, et al. Change in high-sensitive cardiac troponin $\mathrm{T}$ on hypertensive treatment. Clin Exp Hypertens. 2013;35(1):40-44.

26. Narumi T, Shishido T, Kiribayashi N, et al. Impact of insulin resistance on silent and ongoing myocardial damage in normal subjects: the Takahata study. Exp Diabetes Res. 2012;2012:815098.

27. Uetani T, Amano T, Harada K, et al. Impact of insulin resistance on post-procedural myocardial injury and clinical outcomes in patients who underwent elective coronary interventions with drug-eluting stents. JACC Cardiovasc Interv. 2012;5(11):1159-1167.

28. Ding W, Zhang X, Huang H, et al. Adiponectin protects rat myocardium against chronic intermittent hypoxia-induced injury via inhibition of endoplasmic reticulum stress. PLoS One. 2014;9(4): e94545.

29. Rothwell SE, Richards AM, Pemberton CJ. Resistin worsens cardiac ischaemia-reperfusion injury. Biochem Biophys Res Commun. 2006;349(1):400-407.

30. Li SY, Yang X, Ceylan-Isik AF, Du M, Sreejayan N, Ren J. Cardiac contractile dysfunction in Lep/Lep obesity is accompanied by NADPH oxidase activation, oxidative modification of sarco(endo)plasmic reticulum Ca2+-ATPase and myosin heavy chain isozyme switch. Diabetologia. 2006;49(6):1434-1446.

31. Boudina S, Abel ED. Diabetic cardiomyopathy, causes and effects. Rev Endocr Metab Disord. 2010;11(1):31-39.

32. Kwon SH, Pimentel DR, Remondino A, Sawyer DB, Colucci WS. H(2) $\mathrm{O}(2)$ regulates cardiac myocyte phenotype via concentration-dependent activation of distinct kinase pathways. J Mol Cell Cardiol. 2003;35(6): 615-621.

33. Fukui T, Yamauchi K, Maruyama M, Yasuda T, Kohno M, Abe Y. Significance of measuring oxidative stress in lifestyle-related diseases from the viewpoint of correlation between d-ROMs and BAP in Japanese subjects. Hypertens Res. 2011;34(9):1041-1045.

34. Kotani K, Koibuchi H, Miyamoto M, Yamada T, Taniguchi N. Relationship between reactive oxygen metabolites and carotid intimamedia thickness in subjects with hypercholesterolemia. Med Princ Pract. 2010;19(6):496-498.

35. Vassalle C, Bianchi S, Battaglia D, Landi P, Bianchi F, Carpeggiani C. Elevated levels of oxidative stress as a prognostic predictor of major adverse cardiovascular events in patients with coronary artery disease. J Atheroscler Thromb. 2012;19(8):712-717.

36. Takaki A, Ogawa H, Wakeyama T, et al. Cardio-ankle vascular index is a newnoninvasive parameter of arterial stiffness. Circ $J$. 2007;71(11):1710-1714.

37. Jaroch J, ŁobozGrudzien K, Bociaga Z, et al. The relationship of carotid arterial stiffness to left ventricular diastolic dysfunction in untreated hypertension. Kardiol Pol. 2012;70(3):223-231.

38. Sakane K, Miyoshi T, Doi M, et al. Association of new arterial stiffness parameter, the cardio-ankle vascular index, with left ventricular diastolic function. J Atheroscler Thromb. 2008;15(5):261-268.

39. Nakamura $\mathrm{K}$, Iizuka $T$, Takahashi $M$, et al. Association between cardio-ankle vascular index and serum cystatin $\mathrm{C}$ levels in patients with cardiovascular risk factor. $J$ Atheroscler Thromb. 2009;16(4): 371-379.

40. Zizek B, Poredos P. Increased left ventricular mass and diastolic dysfunction are associated with endothelial dysfunction in normotensive offspring of subjects with essential hypertension. Blood Press. 2007;16(1):36-44. 
41. Martí V, Aymat R, Ballester M, García J, Carrió I, Augé JM. Coronary endothelial dysfunction and myocardial cell damage in chronic stable idiopathic dilated cardiomyopathy. Int J Cardiol. 2002;82(3): $237-245$.
42. Arai H1, Yamamoto A, Matsuzawa Y, et al. Prevalence of metabolic syndrome in the general Japanese population in 2000. J Atheroscler Thromb. 2006;13(4):202-208.

\section{Publish your work in this journal}

Diabetes, Metabolic Syndrome and Obesity: Targets and Therapy is an international, peer-reviewed open-access journal committed to the rapid publication of the latest laboratory and clinical findings in the fields of diabetes, metabolic syndrome and obesity research. Original research, review, case reports, hypothesis formation, expert opinion and commentaries are all considered for publication. The manuscript management system is completely online and includes a very quick and fair peer-review system, which is all easy to use. Visit http://www.dovepress.com/testimonials.php to read real quotes from published authors.

Submit your manuscript here: http://www.dovepress.com/diabetes-metabolic-syndrome-and-obesity-targets-and-therapy-journal 